\title{
SPubínSaúde
}

\section{Psoríase e sua ligação com os aspectos psicológicos}

\author{
Psoriasis and its connection with psychological aspects
}

\author{
Daniele Ramos Guedes ${ }^{1 *} \bullet$, Ednalva Santos Viana ${ }^{2}$
}

\begin{abstract}
${ }^{1}$ Mestranda do Curso de Gestão e Saúde Pública, Universidad Columbia Del Paraguai, Asunción, Paraguai, Docente Instituto Macapaense de Melhor Ensino Superior, Macapá, Amapá, Brasil. ²Bacharel em Psicologia, Instituto Macapaense de Melhor Ensino Superior, Macapá, Amapá, Brasil. Autor para correspondência. E-mail: danieleguedes.ap@gmail.com
\end{abstract}

\begin{abstract}
Resumo: Introdução: Os profissionais da área da saúde, em especifico o psicólogo (a) deve ter uma visão para o paciente e considerar seu estado emocional, assim como sugerir tratamento psicoterápico. Objetivo descrever a psoríase e sua ligação com aspectos psicológicos. Sendo uma infecção granulomatosa da pele ou região de união, juntas, ou seja, são conexões naturais existentes entre dois ou mais ossos, imuno-mediada, de base genética, com grande polimorfismo de expressão clínica, que é a existência de dois ou mais fenótipos alternativos comuns, que resulta em respostas imunes contra as células e tecidos. Apesar de apresentar evolução benigna, a psoríase determina uma influência na condição para o bem-estar global do indivíduo, interferindo em suas atividades e tarefas diárias, e pessoas sofrem com o estigma, preconceito nas relações sociais. Trata-se de estudo com levantamento bibliográfico científico de caráter qualitativo que darão suporte e embasamento teórico quanto à relação entre psoríase, aspectos psicológicos, usando fontes de dados documentais, por meio da busca de artigos científicos, em bases de dados eletrônicos no Google Acadêmico, Scielo, a revisão literária, discussões, embasamento teórico examinadas e publicadas através de livros, sítio eletrônico que são desenvolvidas com linguagens de marcação como o HTML e foram selecionadas as referências mais importante para o desenvolvimento do trabalho.
\end{abstract}

Palavras-chave: aspectos psicológicos, psoríase, sistema imunológico.

Abstract: Introduction: Health professionals, specifically the psychologist (a) must have a vision for the patient and consider their emotional state, as well as suggest psychotherapeutic treatment. Objective to describe psoriasis and its connection with psychological aspects. Being a granulomatous infection of the skin or joint region, together, that is, they are natural connections existing between two or more bones, immuno-mediated, of genetic base, with a great polymorphism of clinical expression, which is the existence of two or more phenotypes common alternatives, which results in immune responses against cells and tissues. Despite presenting a benign evolution, psoriasis determines an influence on the condition for the individual's global well-being, interfering in his daily activities and tasks, and people suffer from the stigma, prejudice in social relationships. This is a study with a scientific bibliographic survey of a qualitative character that will provide support and theoretical basis regarding the relationship between psoriasis, psychological aspects, using sources of documentary data, through the search for scientific articles, in electronic databases on Google Scholar, Scielo, the literary review, discussions, theoretical background examined and published through books, website that are developed with markup languages like HTML and the most important references for the development of the work were selected.

Keywords: psychological aspects, psoriasis, immune system.

\section{Introdução}

A Psoríase e sua ligação com aspectos psicológicos afetam muitas pessoas que são acometidas pela doença, bem como outras dermatoses, ou seja, um conjunto de doenças da pele, representada por manifestações alérgicas persistentes que está associada ao stress na sua ação ou resultado ou na piora das lesões que fica muito sensível, deixando o paciente frágil, indefeso e exposto. A própria doença está relacionada não só a lesão do corpo físico, mas, principalmente, a saúde mental e podem causar sofrimento e incapacidade que diversos problemas de saúde, como por exemplo: ansiedade excessiva, cansaço contínuo, mau humor, dores de cabeça constantes, tristeza e angústia frequentes, variação de humor, agitação, irritação, vergonha, ás vezes isolamento social por causa da exposição da pele e outros sintomas. Dados da literatura empírica e teórica que podem ser direcionados à definição de conceitos a relação entre os aspectos psicológicos, como um refletor que toma a forma e a coloração que são impressas pela qualidade dos desejos e pelo ambiente psíquico, que quando não é cuidado pode agravar estado emocional e físico de uma pessoa, ás vezes acarretar ao suicídio. Os profissionais da área da saúde, em especifico o psicólogo (a) deve ter uma visão para o paciente 
e considerar seu estado emocional, assim como sugerir tratamento psicoterápico onde o paciente e psicólogo trabalham juntos para resolver as questões desejadas. As lesões causam desconforto à pessoa, resultam no desequilíbrio da saúde, muitas vezes impedindo ou dificultando atividades básicas do dia a dia, como locomoção e convivência, produz coceira que ás vezes machuca e sangra, acarretando a baixa autoestima, sem vontade de sair para passear, e conviver com outras pessoas, intensificando e agravando os casos, visto que, mesmo sendo uma doença caracterizada por uma ampla diversidade de sinais, e que não tem cura, mas existe o tratamento para aliviar ou prevenir. A pesquisa revelará que diante do problema: Quais os fatores psicológicos e a forma em atender as necessidades básicas dos acometidos pela doença?

Desta forma no primeiro deste estudo, buscou-se compreender mediante a visão de diversos autores, conforme suas respectivas, isto posto um problema do Sistema imunológico, podendo surgir em qualquer parte da pele, sendo mais frequentes no couro cabeludo, cotovelos e joelhos. No segundo momento discorre sobre a psoríase e a relação com os aspectos psicológicos, onde o estresse ainda não esteja bem definido, pois alguns fatores são determinantes para condicionar esses desajustes emocionais.

\section{Revisão}

Proceder -se de publicações científicas em periódicos, livros, anais de congressos etc., segundo Gil (2008), foi elaborado com base no objetivo de reunir as informações e dados que servirão de base para a construção da investigação proposta conforme a temática. Assim o método a ser adotado na pesquisa é de suma importância para se imprimir o caráter científico do estudo a ser examinado. Sendo assim, adotar-se-á a referência teórica pois, traz um conjunto de conhecimentos reunidos em obras de toda a natureza. As buscas documentos oficiais e artigos científicos foram também realizadas nas bases de dados eletrônicos, bases de dados Scielo, foram selecionados artigos em português, cuja publicação entre os anos de 1988 a 2003 que relatam a doença psoríase.

Artigos foram delineados critérios com disposto de atender devidamente aos objetivos assentados como critérios para inclusão, aspectos psicológicos com embasamento de vários teóricos como Gupta e Gupta (2008) sobre "Comorbidade psiquiátrica e psicológica em pacientes com desordens dermatológicas: epidemiologia e manejo", foram publicados ano 2003 e foram excluídos textos que não faz fechamento com a temática proposto. Destarte, foi uma representação normativa de obras consultadas para a elaboração de um texto, artigo, publicações cientifica, permitindo o enfoque maior sobre a Psoríase e a relação com o aspecto psicológico. Nas investigações predominou a utilização de variadas fontes julgadas aptas pela natureza científica da coleta dos seus dados e averiguação das informações contidas (GIL, 2008), filtradas em concordância com a quadro teórico de referência - o materialismo histórico. Foram acessadas via periódicos científicos, livros, dissertações, teses, sites oficiais/especializados.

Realizada uma vasta pesquisa bibliográfica com embasamento teórico de vários autores que deram suporte ao contexto para que assim pudesse ser encontrada a resposta da problematização. Este artigo qualifica-se como levantamento bibliográfico, usando fontes de dados documentais, por meio da busca de artigos científicos, em bases de dados eletrônicos no Google Acadêmico, Scielo, a revisão literária foi selecionada as referências mais relevantes para o desenvolvimento do trabalho.

\section{Psoríase e a visão de vários estudiosos}

Etiologia desconhecida, com evolução crônica com o surgimento de tonsura, acentuada, marcada por uma doença crônica, sendo ainda centro de pesquisa e estudos que buscam mostrar que os acometidos pela psoríase sofrem com o estigma, sensibiliza a beatitude, comprometendo a forma de padrões das pessoas acometidos pela doença além de lidar com o preconceito e muitas vezes excluídos da sociedade, visto que, mesmo não sendo contagiosa, as pessoas sentem-se estigmatizados pela aparência gerado pelas lesões. Saliente que a escandescência da psoríase crônica da pele provoca lesões visíveis no corpo, enfatizando assim os cientistas o aumento dos índices da prevalência de elevada comorbidades como hipertensão, diabetes, sobrepeso e obesidade entre os psoriáticos em relação a população em geral, já que nessa condição tendem a cuidarem menos da própria saúde e praticar menos atividade física. (Proença \& Maia, 1995).

A psoríase tem elevada propensão pelo couro cabeludo e pelas regiões podem ter imenso efeito no auto conceito, aspecto e porte do corpo, apontando para algumas partes como o próprio cotovelo, as mãos, pés, etc onde a lesão exposta de modo frequente envolvida, que atingem a pele do paciente, podem produzir o aparecimento de novas lesões na área traumatizada (Proença \& Maia, 1995). 
Desta maneira, a doença composto pela epiderme é relativamente comum, crônica e não contagiosa, ou seja, que envolve o organismo como um todo e às vezes lesiona as articulações e a região dermatológicas, que tende a manifestar um conjunto de sintomas que varia deformas leves as mais severas dependendo do desenvolvimento, partindo-se e aumentando-se na proporção com os elementos ambientais, genéticos e de comportamento. (Gottlieb, Chao, \& Dann, 2008).

Salientando Sampaio, Castro e Rivitti (1989) Existem mais questões consideradas importantes para o aparecimento da psoríase, sendo a propensão genética de um indivíduo, casos como esse a tendência é poligênica (Um tipo de herança genética, na qual participam dois ou mais pares de genes com segregação independente) resultando em um efeito acumulativo de vários genes envolvidos, o que eleva gradativamente o risco de se obter a doença em similares e parentes de primeiro grau. A psoríase que é considerada como uma condição estressante, pode promover intenso desempenho ao conhecimento e intelectual, as transfigurações, no entanto na apresentação exterior que pode ter efeito no auto conceito e na fisionomia do corpo.

Á psoríase compromete a autoestima e a imagem, onde tem se manifestado com mais precisão em seus portadores mais jovens, já que na maioria dos casos encontram-se sujeitos a encarar a discriminação e o preconceito advindo daquelas pessoas que não conhecem os sintomas. Vale ressaltar que os acometidos adultos têm maior persistência emocional e dependendo da faixa etária vão compreendendo a viver com os aspectos, sintomas da psoríase (Chiozza, 1991).

Na análise dos autores Bork e Brauninger (1998) argumentam que as pessoas com a pele extremamente infecionadas mencionam sentir constrangimento, inquietação, tormento e tristeza, precipuamente quando se tratadas áreas de fácil percepção, pois a exposição é visível e difícil de esconder chamando atenção dos olhares intrigados, ocasionando sinais de uma maneira ruim e tem uma visão extremamente negativa de si mesmo. Conforme dados obtidos pôde-se entender a particularidade e condição de quem tem essa doença, deixa muitas sequelas principalmente em jovens que se preocupam muito mais com a aparência e no estado físico, mental e social, que prescinde comportamento inseguro, negativista e preferindo manter-se em isolamento e por conseguinte o desinteresse de realizar qualquer atividade ou programação que precise se expuser em público.

E na teoria Brophy, Taylor, Blake e Calin (2003) concordam parece sofrer influências de fatores ambientais, infecciosos e imunogenéticos, já que a ocorrência familiar e a presença de determinados antígenos, as pessoas que apresentam as lesões aparentemente exposta tendem-se ter uma restrição e diminuição na condição para o bem-estar a nível emocional, às vezes eminente ao detectado com outras enfermidade, todavia se consideram uma forte desaprovação de características, baseado na aparência consecutivo da doença, entrando em desânimo, abatimento, ansiedade profunda e pode levar ao suicídio, que já é a segunda principal causa de morte em jovens em mais de $5 \%$ das ocorrências,

A doença varia e depende do percurso de cada indivíduo, pois, cada um apresenta quadro diferente, dependendo do seu estado emocional, apesar do alto impacto psicossocial, a intensidade do prejuízo adaptativo pode variar em concordância com a percepção da pessoa, pois cada um difere do outro principalmente na questão emocional. Assim, causando efeito no estado permanente de perfeita satisfação e plenitude das pessoas, e ademais do preconceito proveniente dessaber que acham que é infeciosa. Para que a doença possa estar visível, é necessária a presença de diversos fatores que podem acarretar individualmente, podemos nos basear, o frio, há infecções que se manifestam no decorrer da vida como ao uso impróprio de medicamentos, como por exemplo, antialérgicos ou remédios que podem baixar o efeito da enzima que converte a angiostensina, e certos anti-inflamatórios que possuem a capacidade de aumentar as chances de se contrair a psoríase. (Bork \& Brauninger, 1998).

Existem mais questões consideradas importantes para o aparecimento da psoríase, sendo a propensão genética de um indivíduo, casos como esse a tendência é poligênica (Um tipo de herança genética, na qual participam dois ou mais pares de genes com segregação independente) resultando em um efeito acumulativo de vários genes envolvidos, o que eleva gradativamente o risco de se obter a doença em similares e parentes de primeiro grau. A psoríase acarreta no aumento da morbilidade, transformando o estado físico, mental e social das pessoas acometidas com essa doença, deixando muitas sequelas psicológicas e físicas onde lesões avermelhadas na pele são geralmente fáceis de serem reconhecidos e provoca mudança na aparência, a classificação com relação na imagem física. (Berkow et al., 2003).

Steiner e Perfeito (2003) divisão funcional do sistema imunológico impactam seus portadores emocionalmente e em seus convívios interpessoais, e são através das lesões que coçam constantemente quando se manifesta, sendo recomendando o tratamento através de loções, pomadas, shampoos ou géis para a condição mais leves da doença. Apesar que não influencie na sobrevivência, mas, está claro que causa comoção negativa nos relacionamentos interpessoais que envolve conjuntamente aspectos psicológicos e 
sociais de muitas pessoas, constatado pelos danos interferidos na saúde, oásis, prazer da vida portanto, trabalhando o corpo e mente para lidar com diversos sentimentos principalmente a ansiedade e negatividade (Steiner \& Perfeito, 2003).

Conforme Atkinson, Atkinson, Smith, Bem e Hoeksema (1995), com transfigurações na aparência ou que se manifestam superficialmente e de fácil percepção, e casos pode-se citar onde a psoríase pode enternecer intensamente o comportamento emocional e perceptivo, onde podem ter imenso efeito no auto conceito, aspecto e porte do corpo, apontando para algumas partes como o próprio cotovelo, as mãos, pés, etc onde a lesão exposta.

Para Torrezan (1997) importante enfatizar que a psoríase não é propagada por contágio, conforme as pesquisas histológicas (ramo da ciência que estuda os tecidos biológicos) e manifestam a chamada hiperproliferação celular, ou seja, de células da epiderme.

Segundo Atkinson et al. (1995), ser humano abrange a boa disposição física, mental, psicológica e emocional, incluindo conviver bem com seus semelhantes, como família e amigos e outros fundamentos que influenciam na vida humana que decorrem na conjunção cultural no conjunto de valores em que se compreende como um todo, associados a seus propósitos, possibilidades e preocupações, dentre outras, causado por processos internos, conflitos não resolvidos ou até mesmo traumas infantis, podem ser conscientes ou inconscientes ou ainda motivos íntimos estão em oposição um com o outro.

Contudo, em concordância com os autores as pessoas que se submetem ao isolamento social tem sua alegria, prazer, satisfação um tanto prejudicada, especialmente quando se tratada dos afazeres que não realizam como deveriam, além do maior número dos acometidos serem sucedidos a discriminação diante de indivíduos que não tem discernimento em relação a doença, tornando-se a condição significativa no ponto de vista emocional e social, demostraram sensação negativa no que diz aparência física. (Atkinson et al., 1995).

\section{Psoríase: aspectos psicológicos}

Tal entendimento propõe a relação entre o alto grau de gravidade/visibilidade das lesões que constantemente sensibiliza a saúde das pessoas que tem a doença, desta forma prejudica psicológico e emocional causado pela psoríase. Conforme o autor com propósito de melhor compreender essas concepções com Chiozza (1991), nota-se que portadores sentem-se envergonhados, e muitas vezes quando são acometidas as lesões pelas mãos, não dão as mãos para cumprimentar alguém e sentem vergonha, medo, e desconfiança do que irão perguntar, temem ser rejeitados e sofrem frente a uma sociedade preconceituosa que estabelece padrões ideais de beleza e de adequação, ocasionando o isolamento social, familiar e profissional.

Segundo Gon, Rocha e Gon (2005), abordam as implicações da doença vivenciadas no cotidiano dos acometidos, apresentadas no contexto das interferências físicas, psicossociais e familiares de cada pessoa e seus impactos que chamam atenção para novas estratégias de intervenção por profissionais capacitados, pois a condição constituem fatores que afetam o comportamento do paciente e de seus familiares, acarreta a discriminação, o afastamento, e entretenimento social com outras pessoas.

Desta forma Gon et al. (2005), os autores enfatizam alguns efeitos de comportamentos tendo em vista que produz em muitos casos estigmatização e discriminação, de modo que ocorra um choque negativo no estado constante de satisfação e da felicidade plena, precipuamente pelo desconhecimento da patologia pela sociedade, todavia para minimizar e informar a todos, é viável ações para o esclarecimento a população de forma a diminuir o sofrimento emocional dessas pessoas que externalizaram seus sentimentos através de histórias seus sentimentos de negatividade e essas situações que podem criar traumas para resto da vida se não for cuidado e tratado.

Conforme Goffman (1988), os relacionamentos sociais, como família e amigos e também a saúde, educação, e dentre outros fundamentado na percepção sobre sua existência decorrente do contexto do modo e maneira de vida no agente de valores em que está adentrado, associados aos objetivos, possibilidades, probabilidades e viabilidades, assim o estigma usurpa a pessoa de sua identidade social, esvaindo de seus atributos de humanidade, pois, o julgamento começa a partir da discriminação e do preconceito.

Para Lipp (1991) o acúmulo excessiva de lesões cutâneas de foma váriavel que são aquelas que toma a zonas dessemelhantes da pele, cita-se: mãos, pés, zona anogenital e axilas, aumentam a incapacidade vários órgãos e sistemas, pode ser definido pela dificuldade ou pela necessidade de ajuda para o indivíduo executar tarefas cotidianas básicas ou mais complexas, necessárias para a vida independente na comunidade e tarefas relacionadas à mobilidade, podendo gerar obstáculos em se manter relações sociais, sobretudo quando se trata da forma articular que apresenta a "artrite psoriásica”, ou seja pode causar inflamação em várias articulações, 
simultaneamente às lesões da pele, ou não, embora os sintomas dependam da condição, existem sintomas comuns à maioria das doenças autoimunes, como febre pouco elevada e fadiga, consoante os estudos este problema é dermatológico conhecido como uma doença autoimune.

A psoríase se relaciona a certo mecanismo inflamatório, uma doença que compromete todo o corpo, lidar e aceitar que tem a doença, ou seja, enfrentar e desenvolver uma maneira de modo lidar com a doença, realizando terapias com profissionais qualificados e preparados e não aceitar e não cuidar, buscar tratamento necessário para minimizar os sintomas da doença, pois, cura não há, mas, o controle sim (Silva, 2003).

Por Lipp (1991) o trabalho objetivou conhecer essa temática que é suma importante, assim, concluiu-se que os fatores emocionais que interferem na produtividade pessoal/profissional do indivíduo e o alto grau de stress, ou seja, uma reação do organismo que ocorre quando ele precisa lidar com situações que exijam um grande esforço emocional, nas quais foram responsáveis pelo agravamento e/ou reaparecimento da psoríase.

Para Zachariae et al. (2004) destacam que em diversos acontecimentos e na maior parte dos casos lesam significativamente o contentamento e conforto das pessoas consequentemente sendo preciso prolongar o tratamento com medicamentos e em algumas situações dependendo de cada ocorrência o acompanhamento de profissionais mais qualificados, visto que, podem acarretar a manifestação da depressão ocasionando baixa autoestima, isolamento social, problemas no trabalho, na família, e em outros círculos sociais, por consequência provocando impactos psicológicos, social e econômicos consideráveis na vida das pessoas.

Segundo Gupta e Gupta (2003) sobre a relevância dos fatores psiquiátricos e psicológicos comportamentais clinicamente significativos que afetam negativamente uma doença médica existente e em pelo menos 30\% dos problemas da pele que mais impactam na qualidade de vida, algumas vezes, principalmente casos mais elevados a condição do suicídio.

Desta forma, fatores psicológicos podem induzir no progresso, evolução, adiantamento da psoríase, diante disso o estresse entendido como o fator mais vexatório, uma vez que há um acercamento entre a unidade básica constitutiva do sistema nervoso e aquelas que procede na epiderme (Melo et al., 2019).

\section{Discussão}

Com base nas informações, iniciou-se a leitura e seleção dos textos, ou seja, partiu-se para análise e interpretação do material de acordo com o tema escolhido. A pesquisa bibliográfica é fundamentada por um levantamento de referências teóricas já analisadas, e publicadas por meios escritos e eletrônicos, como páginas de web sites, sendo um conjunto de informações precisas e minuciosas que permite a identificação e recuperação da publicação no todo ou em partes. A priori, foram investigadas relativamente a psoríase que é uma condição particular que deteriora negativamente o organismo e depois priorizadas aquelas mais significativas para o trabalho, desta forma todo o material utilizado refletiu-se em material bibliográfico.

A pesquisa da literatura com suporte por bases eletrônicas de dados, mediante ao método de formar, interpretar e organizar as informações selecionadas a ser seguido para se alcançar a segurança dos dados e pudesse encontrar a explicação satisfatória para a resposta do problema na qual foi colocada em questão.

As lesões de pele deixam evidentes caracterizas como destruidoras da imagem, a pessoa com conhecimento da doença através de sinais e sintomas tem sua vida transformado totalmente perpassando por transformações diárias, tanto na área psicológicas e sociais ou nas atividades de rotina, como nos relacionamentos sociais e interpessoais, embora seja considerada equilibrada a sua evolução (Brito \& Pereira, 2012).

Os artigos selecionados encontram-se descritos de forma analítica conforme no quadro 1 :

Quadro 1. Descrição dos artigos que avaliaram Psoríase e sua ligação com os aspectos psicológicos.

\begin{tabular}{|c|c|c|c|c|}
\hline Autor/ano & Tema & Objetivos & Metodologia & Resultados Encontrados \\
\hline $\begin{array}{c}\text { Melo et.al } \\
\text { (2019). }\end{array}$ & $\begin{array}{l}\text { Influência de fatores } \\
\text { emocionais nas } \\
\text { doenças crônicas de } \\
\text { pele: O estresse como } \\
\text { gatilho para o } \\
\text { desenvolvimento, } \\
\text { reincidência ou } \\
\text { agravamento da } \\
\text { psoríase }\end{array}$ & $\begin{array}{l}\text { analisar a forma como } \\
\text { esses aspectos podem } \\
\text { ensejar o surgimento, a } \\
\text { reincidência ou a } \\
\text { acentuação do quadro } \\
\text { clínico }\end{array}$ & $\begin{array}{l}\text { uma vasta literatura } \\
\text { bibliográfica acerca da } \\
\text { temática }\end{array}$ & $\begin{array}{l}\text { Demonstrada a } \\
\text { importância do tratamento } \\
\text { psíquico e fisiológico, bem } \\
\text { como a necessidade do } \\
\text { desenvolvimento de } \\
\text { estratégias de coping para } \\
\text { enfretamento das situações } \\
\text { sociais envolvidas. }\end{array}$ \\
\hline
\end{tabular}




\begin{tabular}{|c|c|c|c|c|}
\hline $\begin{array}{c}\text { Mazzetti et } \\
\text { al. (1994) }\end{array}$ & $\begin{array}{l}\text { Psoríase e sua relação } \\
\text { com aspectos } \\
\text { psicológicos, stress e } \\
\text { eventos da vida }\end{array}$ & $\begin{array}{l}\text { Avaliar o resultado do } \\
\text { tratamento de controle } \\
\text { do stress emocional com a } \\
\text { redução e a recidiva das } \\
\text { lesões no seu tamanho e } \\
\text { extensão }\end{array}$ & $\begin{array}{l}\text { Na pesquisa de levantamento } \\
\text { de dados, os autores referiram } \\
\text { que a psoríase estava } \\
\text { associada com uma variedade } \\
\text { de problemas psicológicos, } \\
\text { incluindo baixa auto-estima, } \\
\text { disfunção sexual, depressão e } \\
\text { ideação suicida. }\end{array}$ & $\begin{array}{c}\text { Pesquisas demonstram } \\
\text { que, no caso da psoríase, } \\
\text { os sentimentos de rejeição } \\
\text { e de estigmatização podem } \\
\text { estar presentes no } \\
\text { cotidiano do paciente }\end{array}$ \\
\hline $\begin{array}{c}\text { Marques e } \\
\text { Rodrigues } \\
\text { (2011) }\end{array}$ & $\begin{array}{l}\text { Impacto da psoríase } \\
\text { na qualidade de vida } \\
\text { dos pacientes em } \\
\text { tratamento: uma } \\
\text { revisão Sistemática da } \\
\text { literatura }\end{array}$ & $\begin{array}{l}\text { Descrever o impacto da } \\
\text { psoríase na qualidade de } \\
\text { vida dos pacientes } \\
\text { portadores da doença }\end{array}$ & $\begin{array}{l}\text { Culminando o ciclo da } \\
\text { pesquisa de revisão } \\
\text { bibliográfica }\end{array}$ & $\begin{array}{c}\text { Muitas vezes afeta a } \\
\text { qualidade de vida e requer } \\
\text { tratamento prolongado, o } \\
\text { que pode trazer elevados } \\
\text { impactos psicológico, } \\
\text { social e econômico }\end{array}$ \\
\hline $\begin{array}{l}\text { Gupta e } \\
\text { Gupta } \\
\text { (2003) }\end{array}$ & $\begin{array}{l}\text { Psoríase e sua relação } \\
\text { com aspectos } \\
\text { psicológicos, stress e } \\
\text { eventos da vida }\end{array}$ & $\begin{array}{l}\text { Uma avaliação } \\
\text { psicológica e verificar o } \\
\text { fator social, além dos } \\
\text { fatores dermatológicos } \\
\text { preliminares. }\end{array}$ & $\begin{array}{c}\text { Autores referiram que a } \\
\text { psoríase estava associada com } \\
\text { uma variedade de problemas } \\
\text { psicológicos, incluindo baixa } \\
\text { auto-estima }\end{array}$ & $\begin{array}{c}\text { Importância dos fatores } \\
\text { psiquiátricos e } \\
\text { psicológicos em pelo } \\
\text { menos 30\% dos problemas } \\
\text { dermatológicos. }\end{array}$ \\
\hline
\end{tabular}

Fonte: Dados da pesquisa.

Conforme a leitura, análise e interpretação do material, identificou-se que o isolamento social passou a fazer parte do cotidiano de pessoas acometidos pela doença, e afeta na qualidade de vida. Onde muito indivíduo priva-se de atividades de lazer são tímidos, acanhados e problemas de baixa autoestima sentindose insuficientes perante a família, amigos e sociedade, sendo capaz de aumentar os casos de ansiedade e isolamento, sem cura, contando apenas com um tratamento específico para conduzir com medicamentos ou terapia. (Brito \& Pereira, 2012).

De modo geral, a psoríase causa o afastamento, sentimento de indefesa dos vínculos sociais, a maioria das vezes o isolamento social, as pessoas que são acometidas pela doença sentem receio de estar na presença de outras pessoas, sofrem com o estigma, preconceito e afeta na qualidade de vida, sendo oportuno pela supremacia da psoríase que não apresenta carácter grave, ou seja, uma doença branda e não-progressiva considerada a atribuir a alguém ou a algo um estigma e muitas vezes desistindo de muitas coisas, abrindo mão de práticas prazerosas.

\section{Considerações finais}

Foram selecionados textos com fundamentos de forma detalhada a relação entre os aspectos psicológicos, diminuição da autoestima e padrões de vida. Assim, este artigo atende às necessidades dos leitores e esclarecem suas concepções para um pensamento divergente das que se aproximam do preconceito, e proporcionalmente os autores enfatizaram que não é de propagação, ou seja, contagiosa, mas que pode deixar marcas para resto da vida, tendo somente o controle através de terapia ou medicamentos.

Ressaltam que os profissionais da área da saúde, deve conhecer a doença, antes de qualquer apreciação e, especialmente, aprender a habituar-se originalmente com pessoas que tem a patologia, contribuindo para a eliminação do preconceito e discriminação da doença disposto alcançar a garantia da comodidade dos acometidos, as quais as pessoas sentem-se constrangidos pela lesões que são exposta.

Doravante dos conhecimentos existentes sobre a temática obtidas na literatura fica evidente que ainda existem muitas questões e dúvidas a serem levadas em consideração para assim serem investigadas para que possam ser encontrados resultados positivos. Discorrem também que a implicação emocional da doença são consequência de alterações corporais e afeta a imagem da pessoa, o que pode levar à uma situação desagradável, vergonha, isolamento do meio social, do trabalho, amigos e meio familiar. Desta forma observa-se objetiva favorecer positivamente para a exploração visando à montagem de resumos científico, em seguimento, trazer informação adequada para a cidadãos em geral. Fazer oportuno defender que é importante conhecer a doença.

$\mathrm{O}$ estudo atende às necessidades dos leitores, e a pesquisa foi muito gratificante e servirá para abrir um novo campo de estudo, e que servirá de referência para futuros estudos e a consulta literária com a concepção de vários pesquisadores da literatura, que pode auxiliar profissionais que atuam com pacientes portadores da doença. 


\section{Referências}

Atkinson, R. L., Atkinson, R. C., Smith, E. E., Bem, D. J., \& Hoeksema S. N. 1995. Estresse e enfrentamento. In R. L. Atkinson, R. C. Atkinson, E. E. Smith, D. J. Bem \& S. N. Hoeksema. Introdução à Psicologia (11a. ed.). Porto Alegre, RS: Artes Médicas.

Berkow, R., Beers, M. H., Bogin, R. M., \& Fletcher, A. J. (2003). Manual Merck de informação médica: saúde para a família. São Paulo, SP: Manole.

Bork, K., \& Brauninger, W. 1998. Dermatologia clínica: diagnóstico e terapia (2a. ed.). São Paulo, SP: Manole.

Brito, L., \& Pereira, M. D. G. 2012. Variáveis individuais e familiares na psoríase: um estudo com doentes e parceiros. Psicologia: Teoria e Pesquisa, 28(2), 171-180.

Brophy, S., Taylor, G., Blake, D., \& Calin, A. 2003. A inter-relação entre sexo, fatores de suscetibilidade eo resultado na espondilite anquilosante e seus distúrbios associados, incluindo doenças inflamatórias do intestino, psoríase. Jounal Rheumatol, 30 (9), 2054-2058.

Chiozza, L. A. 1991. Os afetos ocultos em psoríase, asma, transtornos respiratórios, varizes, diabetes, transtornos ósseos, cefaléias e acidentes celebrovasculares. São Paulo, SP: Casa do Psicólogo.

Gottlieb, A. B., Chao, C., \& Dann, F. 2008. Psoriasis comorbidities. Journal of Dermatological Treatment, 19(1), 5-21.

Goffman, E. 1988. Estigma. Rio de Janeiro, RJ: Guanabara.

Gon, M. C. C., Rocha, M. M., \& Gon, A. S. 2005. Análise do conceito de estigma em crianças com dermatoses crônicas. Revista Brasileira de Terapia ComportamentalCognitiva, 7(1), 15-20.

Gupta, M. A., \& Gupta, A. K. (2003). Comorbidade psiquiátrica e psicológica em pacientes com desordens dermatológicas: epidemiologia e manejo. American Journal Clinical Dermatology, 4(12), 833-42.

Gil, A. C. 2008. Como elaborar projetos de pesquisa. São Paulo, SP: Atlas.

Lipp, M. E. N. (1991). Estudos experimentais de duas condições de tratamento médico-psicológico a pessoa portadora de psoríase. Revista do Núcleo de Estudos Psicológicos.

Marques, P. P., \& Rodrigues, C. D. S. 2011. Qualidade de vida de pacientes com psoríase: avaliação do índice de incapacidade. Arquivos de Ciência da Saúde, 12(2), 73-6, 2011.

Mazzetti, M., Mozzetta, A., Soavi, G. C., Andreoli, E., Foglio Bonda, P. G., Puddu, P., \& Decaminada, F. 1994. Psoriasis, stress and psychiatry: psychodynamic characteristics of stressors. Acta Dermato Venerreologica Supplementum (Stockh), 186, 62-4.

Melo, M. S. B., Rocha, N. F. L., Magalhães, S. S., \& Sousa, L.L. 2019. Influência de fatores emocionais nas doenças crônicas de pele: $O$ estresse como gatilho para o desenvolvimento, reincidência ou agravamento da psoríase. Id on Line Revista de Psicologia, 13(46), 584-608.

Proença, N. G., \& Maia, M. (1995). Psoríase. In O. L. Ramos \& H. A. Rothschild. Atualização terapêutica: manual prático de diagnóstico e tratamento (17a. ed.). Porto Alegre, RS: Artes Médicas.

Silva, K. S. 2003. Stress em pacientes com psoríase. Trabalho de conclusão de curso (Universidade Camilo Castelo Branco). São Paulo, SP.

Steiner, D., Perfeito, F. L. 2003. A relação entre stress e doenças dermatológicas. In M. E. Novaes (Org.), Mecanismos neuropsicofisiológicos do stress: teoria e aplicação clínica. São Paulo, SP: Casa do Psicólogo.

Torrezan, E. A. 1997. As implicações do stress nas doenças. Revista Psico-USF, 2(1), 13-22.

Zachariae, R., Zachariae, C., Ibsen, H. H. W., Mortensen, J. T., \& Wulf, H. C. 2004. Psychological symptoms and quality of life of dermatology outpatients and hospitalized dermatology patients. Acta dermatovenereologica, 84(3).

\section{Minicurrículo}

Daniele Ramos Guedes. Mestranda do Curso de Gestão e Saúde Pública, Universidade Columbia Del Paraguai, Assistente Social do Município de Ferreira Gomes e Docente Instituto Macapaense de Melhor Ensino Superior, Macapá, Amapá, Brasil. 
Ednalva Santos Viana. Bacharel em Psicologia, Instituto Macapaense de Melhor Ensino Superior, Psicóloga do Município de Ferreira Gomes, Macapá, Amapá, Brasil.

Como citar: Guedes, R.G., \& Viana, E.S. 2020. Psoríase e sua ligação com os aspectos psicológicos. Pubsaúde, 3, a047. DOI: https://dx.doi.org/10.31533/pubsaude3.a047

Recebido: 25 jun. 2020.

Revisado e aceito: 28 jun. 2020.

Conflito de interesse: os autores declaram, em relação aos produtos e companhias descritos nesse artigo, não ter interesses associativos, comerciais, de propriedade ou financeiros que representem conflito de interesse.

Licenciamento: Este artigo é publicado na modalidade Acesso Aberto sob a licença Creative Commons Atribuição 4.0 (CC-BY 4.0). 